\title{
Applications of the PL homotopy algorithm for the computation of fixed points to unconstrained optimization problems
}

\section{ANDREi BozAntAn and VAsile Berinde}

\section{ABSTRACT.}

This paper describes the main aspects of the "piecewise-linear homotopy method" for fixed point approximation proposed by Eaves and Saigal [Eaves, C. B. and Saigal, R., Homotopies for computation of fixed points on unbounded regions, Mathematical Programming, 3 (1972), No. 1, 225-237]. The implementation of the method is developed using the modern programming language C\# and then is used for solving some unconstrained optimization problems. The PL homotopy algorithm appears to be more reliable than the classical Newton method in the case of the problem of finding a local minima for Schwefel's function and other optimization problems.

Acknowledgements. This work was partially financed by European Social Fund through the Sectoral Operational Programme Human Resources Development 2007-2013.

The second author's research was supported by the Grants PN-II-RU-TE-2011-3-239 and PN-II-ID-PCE-2011-30087 of the Romanian Ministry of Education and Research.

\section{REFERENCES}

[1] Allgower, E. L. and Georg, K., Introduction to numerical continuation methods, Springer-Verlag, Berlin, 1990

[2] Berinde, V., Iterative Approximation of Fixed Points, Springer, Berlin Heidelberg New York, 2007

[3] Bozantan, A., An implementation of the piecewise-linear homotopy algorithm for the computation of fixed points, Creative Mathematics and Informatics, 19 (2010), No. 2, 140-148

[4] Cegielski, A., Iterative Methods for Fixed Point Problems in Hilbert Spaces, Lecture Notes in Mathematics, Vol. 2057, Springer-Verlag, Berlin, 2013

[5] Chidume, C. E., Geometric Properties of Banach Spaces and Nonlinear Iteration, Springer, Berlin Heidelberg New York, 2009

[6] Chidume C. E. and Măruşter, Şt., Iterative methods for the computation of fixed points of demicontractive mappings, J. Comput. Appl. Math., 234 (2010), 881-882

[7] Eaves, C. B., Homotopies for computation of fixed points, Mathematical Programming, 3 (1972), No. 1, 1-22

[8] Eaves, C. B. and Saigal, R., Homotopies for computation of fixed points on unbounded regions, Mathematical Programming, 3 (1972), No. 1, 225-237

[9] Herings, P. J.-J. and Peeters, R., Homotopy methods to compute equilibria in game theory, Economic Theory, 42 (2010), No. 1, 119-156

[10] Istratescu, V. I., Fixed Point Theory. An Introduction, Kluwer Academic Publishers, 2001

[11] Kuhn, H. W., Simplicial approximation of fixed points, Proceedings of the National Academy of Sciences of the United States of America, 61 (1968), No. 4, 1238

[12] Lemke, C. E., Bimatrix equilibrium points and mathematical programming, Management science, 11 (1965), No. 7, 681-689

[13] Merrill, O. H., Applications and extensions of an algorithm that computes fixed points of certain upper semi-continuous point to set mappings, Ph. D. thesis, University of Michigan., Ann Arbor, Michigan, 48106, USA (1972)

[14] Pohlheim, H., Examples of objective functions, http: / / www . geatbx. com (2006)

[15] Scarf, H., The approximation of fixed points of a continuous mapping, SIAM, Journal on Applied Mathematics, 15 (1967), No. 5, 1328-1343

[16] Scarf, H. and Hansen, T., The computation of economic equilibria, Yale University Press New Haven, Conneticut, (1973)

[17] Thele, R. L., Iterative techniques for approximation of fixed points of certain nonlinear mappings in Banach spaces, Pacific J. Math., 53 (1974), 259-266

Department of MAThematics AND COMPUter SCIENCE

NORTH UNIVERSITY OF BAIA MARE

VictORIEI 76, 430122 BAIA MARE, ROMANIA

E-mail address: andrei.bozantan@gmail.com

E-mail address: vberinde@ubm. ro 